\title{
FILOSOFIA E DISCURSO NA CIÊNCIA DA INFORMAÇÃO: TESSITURA DE ENCONTROS
}

\author{
Solange Puntel Mostafa \\ Professora Livre-Docente do curso de graduação em Ciências da Informação, Documentação e \\ Biblioteconomia na Universidade de São Paulo, Ribeirão Preto, SP, Brasil. E-mail: \\ smostafa@terra.com.br.
}

Igor Soares Amorim

Professor do departamento de Ciência da Informação na Universidade Federal de Santa Catarina, Florianópolis, SC, Brasil. E-mail: amorim.igors@gmail.com.

Lucília Maria Abrahão e Sousa

Professora Livre-Docente do curso de graduação em Ciências da Informação, Documentação e Biblioteconomia e do Programa de Pós-Graduação em Psicologia na Universidade de São Paulo, Ribeirão Preto, SP, Brasil. E-mail: luciliamsr@uol.com.br.

\begin{abstract}
Resumo
Aborda o conceito filosófico de rizoma na teorização de Gilles Deleuze e Félix Guattari para desfazer mal entendidos na literatura recente de Ciência da Informação. Explana a dinâmica de criação conceitual na Filosofia e na Ciência, entendendo-as como movimentos entre o virtual e o atual. Em seguida aborda o deslizamento de planos entre Filosofia, Arte e Ciência para ser possível compreender a absorção do conceito filosófico de rizoma pela Ciência da Informação. Apresenta a organização e fluxo da informação pensados inicialmente com a noção de árvore caminhando mais recentemente para a noção de rizoma ou rede. Por fim aproxima as teorizações da filosofia da diferença e da análise de discurso da escola francesa para iluminar ainda mais os mal entendidos sobre a transposição conceitual na Ciência da Informação.
\end{abstract}

Palavras-chave: Rizoma. Ciência da Informação. Rede. Filosofia. Discurso.

\section{PHILOSOPHY AND DISCOURSE IN INFORMATION SCIENCE: TEXTURE OF ENCOUNTERS}

\begin{abstract}
Discusses the philosophical concept of 'rhizome' such as Gilles Deleuze and Félix Guattari have posed to undo misunderstandings in the recent literature of information science. Explains the dynamics of conceptual creation in philosophy and science, understanding them as movements between the virtual and the actual. Then addresses the sliding planes between Philosophy, Art and Science to clearly understand the absorption of the philosophical concept of 'rhizome' in Information Science. Presents the organization and flow of information initially thought with the notion of 'tree' and most recently moved towards the notion of 'rhizome' or network.
\end{abstract}

Keywords: Rhizome. Information Science. Network. Philosophy. Discourse.

\section{Introdução: filosofia e ciência}

Temos falado com certa insistência do conceito filosófico no campo da informação, pois aprendemos com Deleuze e Guattari (D \& G) que filosofar é criar conceitos. Sempre que 
falamos em conceitos, estamos filosofando na direção de compreendê-los; assim, o título dessa revista "Filosofia da Informação" é um convite à criação conceitual.

Notamos nos ensinamentos de D \& G (2010) certas diferenças entre Filosofia e Ciência, trata-se de dois planos diferentes; dessa forma sempre que nos referimos à Ciência da Informação estamos situados em um plano. Se estamos no trabalho de tecer uma Filosofia da Ciência da Informação, estamos num plano de imanência, que é diferente do plano da própria Ciência da Informação; isso porque o plano da ciência de todas as ciências, sejam humanas, sociais ou exatas é sempre um plano de soluções situadas e circunstanciadas a um tempo e a um espaço determinados. Dizemos, então, que o plano da ciência é referencial, ou seja, o plano de referencias das ciências. Já o plano da Filosofia não é parcial como um conjunto científico; ele é mais amplo como se pudéssemos pensar um horizonte dos acontecimentos, fora do tempo e de qualquer espaço determinado. O plano de imanência da Filosofia é como um Uno-Todo com traços diagramáticos, dizem os filósofos franceses. Movimentos do infinito, intuições. E, no entanto, esses movimentos não existem separados ou independentes dos conceitos que irão dar consistência ao plano.

Os conceitos são como regiões do plano de imanência. Se o plano é o solo absoluto da filosofia e é como um crivo no caos, os conceitos operam um novo corte ao dar contornos variáveis ao plano. Se é difícil pensar nesse nível de abstração, os filósofos esclarecem que o plano de imanência é o que deve ser pensado mas, ao mesmo tempo, não pode ser pensado visto que é apenas intuído. Intui-se o plano e criam-se conceitos que o habitam. D \& G (2010) são muito generosos nessas explicações que ocupam grande parte do livro $\mathrm{O}$ que é a Filosofia?, livro que nos parece um mágico papiro que se abre e se fecha em velocidades variáveis enquanto enrola e desenrola os conceitos propostos para a filosofia, a ciência e as artes.

Estamos falando de plano e de conceitos porque para esses autores, o papel da filosofia é criação de conceitos, mas os conceitos não estão soltos no mundo - situam-se num plano e são exclusivos da filosofia. A ciência cria algo diferente dos conceitos filosóficos, as funções que diferem do conceito não apenas por uma questão terminológica, mas pela forma como atualizam o virtual: os conceitos dão conta do acontecimento que é incorporal e invisível e as funções lidam com corpos e estados de coisas. A filosofia, nesses termos, tem plano, conceitos e até personagens (necessariamente conceituais) que outra vez são diferentes também dos personagens psico-sociais dos romances e dos observadores parciais das ciências, esses, intercessores em um domínio que captam uma perspectiva.

O conceito é precioso à filosofia, pois ele confere consistência ao plano extraindo 
desses seus componentes. Da mesma maneira, a ciência cria suas funções entre variáveis resultantes do desaceleramento do caos, as quais compõem o plano de referência. Assim, as funções sempre rementem a um sistema de referência, que é em si uma pré-seleção de ordenadas intensivas. Os conceitos são formas próprias da filosofia de atualizar o virtual, preservando as velocidades do virtual, por isso são dinâmicos.

Já as funções também atualizam o virtual, porém abdicam das velocidades em nome de referências. As funções são relativas aos estados de coisas, às coisas ou aos corpos. Elas são estabilizadas através dos functivos, que são justamente variáveis resultantes do desaceleramento do caos. Assim, as funções vão adquirindo densidade, por meio de atualizações operadas por entre functivos e, então, são percebidas e apreendidas por uma força, o observador parcial. Destarte, o percurso da ciência se faz na construção de eixos que duram um certo tempo, desenvolvidos e reinventados por bifurcações no plano de referência. Por isso, os filósofos franceses dizem que "a ciência é paradigmática, enquanto a filosofia é sintagmática" (DELEUZE; GUATTARI, 2011, p. 147).

Podemos dizer que Filosofia e Ciência são diferentes porque a ciência opera em um plano de referência e dá conta do estado das coisas, enquanto a filosofia o faz em um plano de imanência e preocupa-se com a consistência de um acontecimento.

\section{0 deslizamento dos planos}

Em que pese a diferença de planos entre a filosofia e a ciência não nos esqueçamos que ambas são formas de pensamento e como tal esbarram umas nas outras, superpõem-se, convivem, deslizam e se conectam em seus diferentes devires. Ciência, Arte e Filosofia são formas de pensamento que bifurcam continuamente, isto é, desviam-se ou multiplicam-se, mas nunca fazem síntese, isto é, nunca fazem a mesma coisa. Não lidam com os mesmos elementos ou indivíduos. Traçam planos específicos, algumas vezes paralelos, em outras, entretecem planos em deslizamento, como se fossem acrobacias. Sugerimos a imagem abaixo em outra oportunidade (MOSTAFA; NOVA CRUZ, 2009, p 96). 
Figura 1: Deslizamentos dos planos

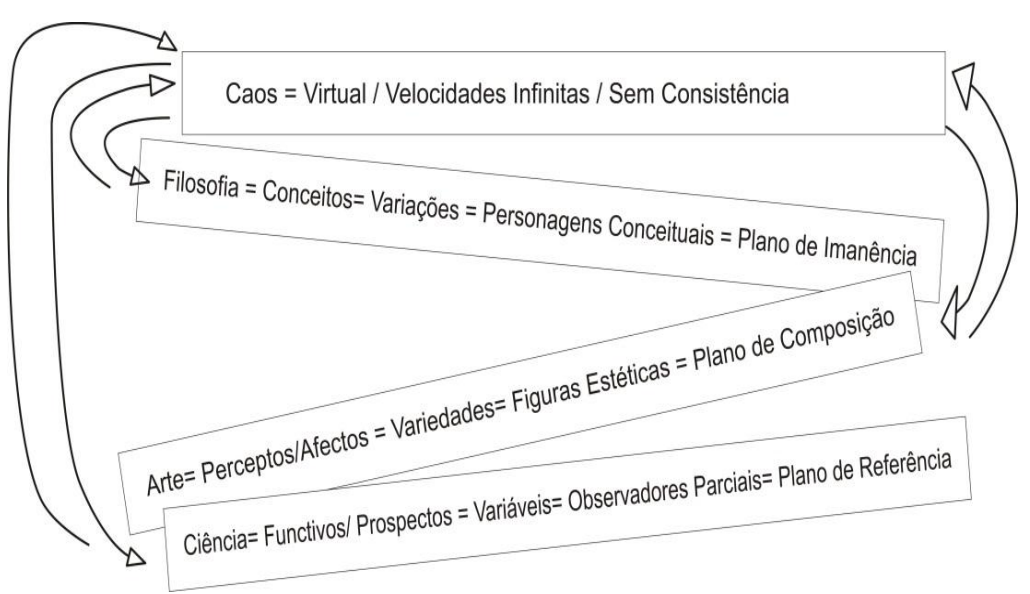

Fonte: MOSTAFA; NOVA CRUZ, 2009, p 96.

A filosofia é o ato da criação de conceitos que visa apreender o caos em sua infinitude. A ciência é um sistema discursivo reflexivo e comunicativo, composto de funções e proposições, que lidam com o caos sempre o remetendo a referências. Embora não possam ser sintetizados, tanto os conceitos como as funções são multiplicidades, mas que diferem em natureza. A ciência cruza incessantemente a possibilidade de conceitos, e os conceitos aludem à ciência; esse cruzamento e essa alusão são tubulações permissivas do deslizamento entre planos. Tanto os conceitos podem gerar funções e proposições nas ciências, como a ciência pode incitar conceitos na filosofia.

É importante sabermos que arte, filosofia e ciência não se colocam como níveis de uma mesma projeção, mas têm "independência respectiva, uma divisão do trabalho que suscita entre elas relações de conexão" (DELEUZE; GUATTARI, 2010, p.110), e seus planos "superpõem-se, convivem, deslizam uns sobre os outros" (MOSTAFA; NOVA CRUZ, 2009, p. 96). É importante entendermos o deslizamento entre os planos da filosofia e da ciência para compreendermos a apropriação importante que a Ciência da Informação tem realizado acerca do conceito filosófico de rizoma.

\section{Da árvore à rede: movimentos na Ciência da Informação}

Na simples análise histórica sobre a evolução das classificações decimais, percebemos que o objeto com o qual a Biblioteconomia e a Ciência da Informação lidam vem alterando suas características. Há movimentações no plano de referência da Ciência da Informação e 
Biblioteconomia, que implicam em renovações dos discursos da área.

Um dos fatores a notar é a mudança da preeminência do modelo de árvore, o qual remonta ao arquétipo interpretativo do fenício neoplatônico Porfírio (234 - 305? d.C.) para o modelo de rede. Se Dewey propunha uma organização em árvore rigidamente desdobrada pela dicotomia gênero-espécie, Otlet e La Fontaine já impregnado pelo modelo de rede neural transposto para a sociologia por Gabriel Tarde (MATTELART, 2002), flexibilizaram essa perspectiva pelo emprego de sinais para representar relacionamentos não hierárquico de assuntos.

Do mesmo modo que o indiano Ranganhatan e o grupo inglês chamado Classification Research Group (CRG) contribuíram decisivamente para a facetação dos assuntos, possibilitando a composição de redes interconectadas pela maneira mesma como os assuntos manifestam-se (BROUGHTON, 2012; PIEDADE, 1983; OLSON, 2011). Contudo na classificação de Otlet e La Fontaine, e mesmo nas classificações facetadas, há pontos centrais na rede, pontos que concentram maior trama de conexões e que estruturam hierarquias, preservando a formalidade lógica. A perda da noção desse pivô na rede se dá com o desenho do Memex de Bush (1945), e sua reinvindicação de estruturas associativas, tais como a mente humana, para a organização de informação. Destacamos que esse movimento não finda o modelo e as classificações em árvores, que até hoje são imprescindíveis à prática e teoria da área, mas coloca em questão novas perspectivas à ciência da informação.

Outra via que traz à tona a rede, enquanto modelo interpretativo, é trazida pelos estudos métricos da informação, as quais pretendem mapear os fluxos e conexões de informações, suas fontes ou referências. Principiada nos anos de 1960, a bibliometria vem se institucionalizando ao longo dos últimos quarenta anos como uma disciplina voltada para a comunicação de informações em vários meios especialmente na ciência, e contribuindo para os estudos da organização da informação ao passo que aproxima os estudos de frequência terminológica aos preceitos da garantia literária. (KOBASHI; SANTOS, 2006). Os produtos da bibliometria resultam em mapas que destacam as relações ou associações entre distintas entidades, revelando redes de produção de informação e conhecimento.

\section{Rizoma como trama de conexão}

Considerando a emergência da noção de rede na Ciência da Informação, acreditamos que o conceito filosófico de rizoma pode ser deslizado ao plano de referência da área. Dias e Nassif (2013) argumentam que a incorporação do conceito de rizoma à Ciência da Informação 
é, por vezes, prejudicial, ao não preservar o sentido original que os filósofos Deleuze e Guattari conferiram a ele. Discordaremos decisivamente desta compreensão. Abordaremos dois artigos que transcrevem rizoma em seu corpo, também presentes na análise de Dias e Nassif (2013), Pinheiro e Silva (2008) e Monteiro (2003), autoras escolhidas naquela análise como exemplos mal sucedidos do emprego do conceito de 'rizoma' na ciência da informação. Pinheiro e Silva (2008) entendem o rizoma deleuze-guattarriano como análogo ao conceito de complexidade e como metáfora da noção de rede, enquanto que Monteiro (2003) utiliza o conceito filosófico para explicar um novo tipo de escrita permitida no ciberespaço, a hipertextal, a qual não é necessariamente linear, mas feita de atalhos e interconexões que ligam diferentes textos.

D \& G estão interessados na criação pelo pensamento, seja na filosofia, ciência ou arte. Há criação quando um filósofo, cientista ou artista mergulha no caos e o traz ao atual. Do virtual ao atual, é este o movimento do pensamento e da criação. O conceito de rizoma expressa a abertura operacionalizada pelo mergulho dos criadores nos planos, é o contato com o virtual, onde tudo é intensidade e velocidade, onde se realizam os agenciamentos, isto é, as conexões maquínicas entre as cadeias semióticas, biológicas, sociais, econômicas, etc. Tratase de um incessante conectar - multiplicidade! É o todo menos sua unidade ( $\mathrm{n}-1)$ (DELEUZE; GUATTARI, 2011).

Tanto o plano de imanência quanto o de referência são em si rizomáticos, com diversas entradas, sem começo nem fim, mas um todo-múltiplo, que não para de perpetrar novas conexões. Não há representação ou reprodução no rizoma, mas tudo segue uma pragmática do possível de maneira que o rizoma é a fonte do devir, das mudanças, das atualizações. O rizoma é integrante do movimento de criação, do virtual ao atual, na filosofia, arte ou ciência; ele articula o atual ao virtual. Entretanto, não é só no mergulho criador, mas sim na emersão atualizadora também; desse modo, o rizoma faz-se por cartografia e não por decalque. A cartografia é fazer mapas por meio de experimentações, é construir, criar, é aqui que está o mergulho do filósofo, cientista ou artista. O mapa é aberto, conectável, flexível, performático. É o criar fazendo. O exercício de criação exige isso, essa saída do decalque, a desterritorialização, à ida ao virtual, cartografando. Porém, é necessário a volta, não ao mesmo, mas a um diferente atualizado, este é o decalque. O decalque é uma imagem do mapa, mas uma imagem não idêntica, pois na captura dessa imagem estabilizam-se e se neutralizam as multiplicidades. O que o decalque reproduz são os impasses, bloqueios, pontos de estruturação do mapa. Assim, o decalque é uma entrada e a saída do rizoma (DELEUZE; GUATTARI, 2011). 
Na Biologia, rizoma é um caule, geralmente subterrâneo, com forma parecida de raiz, que acumula nutrientes podendo formar tubérculos, e é caracterizado pela capacidade de emitir novos ramos em qualquer parte de sua extensão. Na perspectiva biológica, podemos inferir que os functivos e prospectos dão conta de permitir a significação discursiva de rizoma: os prospectos dizem respeito a noção de planta e vegetal, de sua relação com a terra, de onde absorve água e nutrientes, também os aspectos nutritivos da planta; já os functivos estabelecem as condições do entendimento do que é um planta, um ente real no mundo. Os functivos desaceleram o caos e permitem a constituição de proposições e condições de verdade. $D$ \& G trazem essa noção de interação entre planta enquanto tecido vegetal, água, nutriente, a dinamicidade dos brotos que nascem a qualquer ponto do rizoma, sua presença subterrânea, tudo isso, criando um conceito filosófico.

O conceito de rizoma de D \& G é filosófico, está sobre um plano de imanência, mas deslizou da biologia à filosofia, era um prospecto sobre um plano de referência, mas que foi deslocado. Traçou-se um plano e dele levantou-se os componentes e se firmou o conceito. No trecho seguinte de Mil Platôs, D \& G revelam esse deslocamento nos seguintes termos:

Um rizoma como haste subterrânea distingue-se absolutamente das raízes e radículas. Os bulbos, os tubérculos, são rizomas. Plantas com raiz ou radícula podem ser rizomórficas num outro sentido inteiramente diferente: é uma questão de saber se a botânica, em sua especificidade, não seria inteiramente rizomórfica. Até animais o são, sob sua forma matilha; ratos são rizomas. As tocas o são, com todas suas funções de hábitat, de provisão, de deslocamento, de evasão e de ruptura. O rizoma nele mesmo tem formas muito diversas, desde sua extensão superficial ramificada em todos os sentidos até suas concreções em bulbos e tubérculos [...]. Há o melhor e o pior no rizoma: a batata e a grama, a erva daninha. Animal e planta, a grama é o capim-pé-de-galinha (DELEUZE; GUATTARI, 2011, p. 22).

$\mathrm{Na}$ citação acima notamos o deslocamento do plano, que num primeiro contato pode nos parecer um simples deslocamento de significação, mas não se restringe a isso. Vai além, pois se passa no âmbito das intensidades, é um agenciamento que conecta a noção de rizoma ao conjunto de toda obra dos autores na filosofia e psicanálise, colocando em jogo com noções políticas, ao confrontar o sistema arbóreo com o pensamento da multiplicidade, a noção de rede, etc.. O deslocamento promovido é um ato criativo, que traz uma nova dinâmica na filosofia, gera movimentos sobre o plano de imanência. Assim, voltando ao conceito de rizoma na ciência da informação, cabe-nos identificar os deslocamentos e os movimentos que poderiam se dar de duas formas: na utilização filosófica do conceito de rizoma para filosofar sobre a ciência da informação; ou o deslizamento do conceito filosófico de rizoma para um plano de referência. 
No artigo de Pinheiro e Silva (2008) foi objetivado o levantamento das redes de citações nos principais periódicos brasileiros da área entre os anos de 2001 e 2005, utilizando de métodos bibliométricos. Para as autoras "As citações podem ser consideradas os elos de uma rede, na qual os pesquisadores são os nós" (PINHEIRO; SILVA, 2008, p.39). Os textos desses pesquisadores trazem mapas, links, redes que revelam as conexões entre autores e entre documentos do campo, sendo um orgânico crescente por si mesmo. As autoras recuperam a ideia de autopoiese de Maturana e Varela, que destacam a dinamicidade dessas redes, denominando-as redes de cognição. Assim, a atenção volta-se às redes estabelecidas pelas citações de artigos de revistas com Qualis A, utilizando análise de citações e de co-citações, considerando rede como

[...] composta de nós e relações, e, quando essas relações são estabelecidas para a produção do conhecimento, as redes podem ser denominadas redes cognitivas. Na rede analisada, os nós são compostos pelos trabalhos citantes e citados, pelos autores dos artigos citantes e pelos autores dos trabalhos citados. Assim, estudar a rede cognitiva da área implica considerar não somente cada pesquisador ou o conjunto deles, mas também as relações que se estabelecem, diretamente pela colaboração e co-autoria em trabalhos, ou indiretamente por meio das citações que fazem aos mesmos documentos e autores (PINHEIRO; SILVA, 2008, p.42).

Consta dos resultados do artigo elementos externos que influenciam nos relacionamentos entre os membros da rede, como a proximidade institucional dos autores que implica numa maior probabilidade de citação, o que estabelece um "dentro" e um "fora" da rede, e relações de diferentes níveis. No artigo de Monteiro (2003), a autora afirma que o ciberespaço é uma causa de desmaterialização da informação, questionando o papel da representação do suporte enquanto portador de significado. O significado é sempre submetido a um virtual, a diferentes possibilidades, e isso, para a autora, ficou mais claro com o ciberespaço, enquanto um ambiente dinâmico para composição e compartilhamento de signos/textos, "o virtual é o principal atributo do ciberespaço, porque ele demostra e faz possível identificar a escritura rizomática, no hipertexto" (MONTEIRO, 2003, p. 10-11). Dessa maneira, a noção de rizoma é alcançada pelo hipertexto, que permite novas conexões entre signos no ciberespaço, onde há sempre um outro possível, um virtual:

O hipertexto, nas redes digitais, está desterritorializado, graças aos seus dispositivos, dentre deles o 'link' que faz a ligação de contexto entre os enunciados e os conteúdos, estabelece o vínculo entre os vários nós, tornando o espaço (do ciberespaço) além de contínuo, contíguo também [...] O hipertexto certamente não se trata do mesmo texto impresso, estático, linear, preso na materialidade do objeto. Ao que parece, dada a hibridização e virtualidade, tanto das linguagens, quanto do meio, o conhecimento produz signos que geram outros signos, mas estes não se tratam, obrigatoriamente, 
de significantes (no sentido restrito do termo) (MONTEIRO, 2003, p. 6-7).

Para a autora "as bases filosóficas do hipertexto encontram-se no conceito de 'rizoma', de Deleuze e Guattari" (MONTEIRO, 2003, p. 7), afirmando que os "indexadores (mecanismos de busca) da Internet, como modelo de organização do conhecimento, detêm os mesmos atributos do rizoma, operando na multiplicidade do sentido da representação hipertextual à recuperação da informação e do conhecimento" (MONTEIRO, 2003, p. 7). Aqui, rizoma é a realização da multiplicidade de signos, linguagens e sentidos, uma nova pragmática de produção da escrita e da organização do conhecimento que é conscientemente atrelado aos movimentos do virtual (potencial) no mundo digital. Monteiro (2003) defende que os hipertextos na web operam pela multiplicidade, rizomaticamente, sendo possível “entrar", "saltar" por "nós semióticos", o eu torna possível a conjunção e... e... das obras e das buscas de informações realizadas no ciberespaço.

Entendemos que tanto Pinheiro e Silva (2008) como Monteiro (2003) não pretendem em seus respectivos artigos uma construção metodológica de nome rizoma, mas procuram fazer uso do termo, visando explicar a forma como a rede de citações ou a estrutura hipertextual no ciberespaço podem ser visualizadas estética ou filosoficamente. Ambos os textos inovam ao repetirem o signo "rizoma"; inovam a significação de rizoma não merecendo as restrições apontadas por Dias e Nassif (idem), pois inovação aqui não poderá ser confundida com deformação. Portanto há um rizoma como conceito filosófico em Deleuze-Guattari, um rizoma-rede textual-cognitivo em Pinheiro e Silva (2003), e um rizoma signo-links que põe em jogo um insistir do virtual (compreendido enquanto potência, não como digital) em Monteiro (2003). Assim como Deleuze e Guattari atualizam o conceito de rizoma da botânica para o plano filosófico, as autoras, ao repetirem o signo, atualizam-no em um novo plano, aproximando-o e afastando-o de diferentes componentes, functivos e prospectos.

Contudo, destacamos que uma coisa é mobilizar um conceito filosófico como metáfora em sentido pedagógico-metafórico, outro é fazer movimentos filosóficos, traçar um plano de imanência, levantar componentes fazendo-os habitar esse plano e erigir conceitos, tal como foi feito na criação dos conceitos de linguagem documentária menor e informação-afeto (MOSTAFA; NOVA CRUZ, 2011; 2014).

Pinheiro e Silva (2003) invocam o signo rizoma para referirem-se à dinamicidade das redes cognitivas de citações. Monteiro (2008) utiliza o termo como meio de compreender a dinâmica dos hiperlinks no ciberespaço. São dois usos diferentes. Podemos dizer que Pinheiro 
e Silva quase que fazem um uso científico do signo rizoma, mas a intenção das autoras não é exercer um deslocamento de planos (de imanência ao plano de referência), tampouco é fazer filosofia, reterritorializar sobre o conceito de rizoma. Assim o uso é análogo, paralelo, metafórico. Monteiro (2008), por sua vez, procura trabalhar com o conceito filosófico. A autora coloca-se o problema da nova escrita concebida no ciberespaço, afirmando que o rizoma é como uma imagem comparativa, que serve de referência explicativa da dinâmica dos hiperlinks.

Os desdobramentos dos pensamentos deleuzianos são diversos. Em seu abecedário, Deleuze nos fala que não deseja ter discípulos ou escola, "A escola é o contrário do movimento", mas é incitado pela ideia de movimento... "Quero lançar noções e conceitos que se tornem correntes, que se tornem não exatamente ordinárias, mas que se tornem ideias correntes, que possam ser manejadas de vários modos". (DELEUZE, 2014). A utilização que Pinheiro e Silva (2003) e Monteiro (2008) fazem do termo rizoma permite colocar o conceito em movimento, numa corrente, pois são manejos próprios do conceito filosófico do pensador francês. Assim também é o exercício de fazer filosofia da ciência da informação, criar conceitos filosóficos para a ciência da informação é estar nesse movimento deleuziano, a um modo específico ou diferente (MOSTAFA, 2013).

O exercício das criações conceituais de linguagem documentária menor e de informação-afeto também são desdobramentos da filosofia deleuziana; mas desdobramentos diferentes que os efetuados por Pinheiro e Silva (2003) e por Monteiro (2008), pois os conceitos filosóficos, eles pretendem dar contar do virtual em seu infinito, levantando-se sobre um plano de imanência da filosofia da ciência da informação.

Linguagem Documentária Menor (LDM) como conceito filosófico é um de instrumento rizomático, uma tentativa de fazer a língua presente na linguagem documentária (maior) entrar em devir, exceder-se em si e fugir da palavra de ordem das classificações clássicas e gerais dos saberes, como a de Dewey, Otlet e La Fontaine ou os tesauros e sua flexível, porém limitada sintaxe. O conceito de LDM nasce por ressonância, emitida pela filosofia e tem vizinhança com outros conceitos da filosofia da ciência da informação, como o de classificação descritiva por afetos ou informação-afeto (MOSTAFA; NOVACRUZ, 2011; 2014).

Gostaríamos ainda de refletir um pouco sobre os estudos discursivos para tatear o objeto da informação e seu campo. Temos construído algumas aproximações entre a teorização de Michel Pêcheux em sua compreensão clássica sobre a noção de discurso e a noção de acontecimento em Gilles Deleuze (ROMÃO e MOSTAFA, 2003). É preciso 
registrar nosso entendimento de que Deleuze não desenvolve uma filosofia da linguagem justamente porque a linguagem não é central para ele (lembremos que o rizoma não tem centro pois a linguagem é um dos elementos do rizoma, mas não é central), ao passo em que para Pêcheux (1997), a linguagem é modo de inscrição do sujeito e da historicidade. Apreciamos a noção pecheutiana de discurso por ela lidar com a noção de efeito: o discurso é efeito entre interlocutores, nunca está dado de modo pronto ou acabado, convocando-nos a pensar a palavra em seu constante, tenso e inquieto movimento com as condições de produção.

Para ele, o sujeito do discurso coloca em fluxo palavras já ditas antes em outro lugar, e que já tiveram seus usos sociais estabelecidos e tensionados em diferentes momentos sóciohistóricos. Existe assim uma memória discursiva, uma memória do dizer que funda-se como uma propriedade constitutiva da linguagem e do sujeito, apontando o primado do interdiscurso em cada palavra atualizada. Em outros termos, há o saber discursivo sobre o mundo que está latente na linguagem, que sustenta o que é dito a partir do que já foi posto em outros momentos e que lateja a cada nova (re)tomada de dizer. Esse conceito abre-nos a possibilidade de estabelecer aqui uma conexão com a noção-chave de rizoma. Do mesmo modo como rizoma inscreve uma rede de conectividade e uma articulação de relações em curso, o discurso também o faz a partir de efeitos de sentido já postos ou silenciados. Também o discurso articula-se de forma rizomática, construindo-se como "dispersão de ruínas" (MAINGUENEAU, 2005, p.19) e como rede de sentidos dis-postos pela via do entrelaçamento entre regiões da memória discursiva definida como "espaço discursivo como rede de interação semântica" e "processo de interincompreensão" (2005, p. 13).

Tomamos o pensamento de Pêcheux (1999, p. 52) a partir do qual passamos a tecer uma relação entre a memória do discurso e o acontecimento discursivo. Vejamos. A questão é saber onde residem esses famosos implícitos, que estão 'ausentes por sua presença' na leitura da sequência: estão eles disponíveis na memória discursiva como um fundo de gaveta, um registro do oculto?

Vale registrar que esse "papel da memória" opera de modo a sustentar a possibilidade de todo dizível, a inscrição de toda e qualquer palavra já que tanto o efeito de regularização quanto o de ruptura depositam-se sobre/sob as palavras já ditas por outrem. Tal jogo amparado pelo já-lá assegura que o moinho de vento da linguagem continue a girar, produzindo acontecimentos e deslocamentos que poderão instalar outra regularidade na ordem do repetível já que

[...] a memória tende a absorver o acontecimento, como uma série 
matemática prolonga-se conjecturando o termo seguinte em vista do começo da série, mas o acontecimento discursivo, provocando interrupção, pode desmanchar essa 'regularização' e produzir retrospectivamente uma outra série sob a primeira, desmascarar o aparecimento de uma nova série que não estava constituída enquanto tal e que é assim o produto do acontecimento; o acontecimento, no caso, desloca e desregula os implícitos associados ao sistema de regularização anterior. (PÊCHEUX, 1999, p. 52).

O que se coloca aqui é pensar o discurso enquanto tensão entre a memória e a sua atualização, o que nos convoca a indagar se a justaposição de diferentes zonas do já-dito e do acontecimento não teriam um desenho rizomático. Julgamos que sim, pelo eixo de conexões e pelos efeitos de combinação que o rizoma instala. Assim, é da ordem do repetível que se articula o esburacamento do mesmo e o surgimento de outras articulações de efeitos de sentido em uma combinação datada historicamente, eis a tessitura do discurso.

Nesses termos o autor (1999, p. 53) afirma "sob o 'mesmo' da materialidade da palavra abre-se então o jogo da metáfora, como outra possibilidade de articulação discursiva"; e tal jogo articula-se em dadas condições de relação com o poder. Trazemos aqui o enunciado que Pêcheux (1990) analisou quando da vitória do presidente Mitterand dos anos 80, "on a gagné", que antes era um grito de vitória percebido apenas nos estádios de futebol quando das finais de campeonato. E, no dia da eleição do primeiro presidente denominado de esquerda na França, esse dizer ganhou as ruas da cidade sendo um canto de outra vitória, aquela antes do futebol agora comparece deslocada como vitória de muitos torcedores unidos em uma só torcida, a torcida de um país inteiro.

\section{Considerações finais}

A certeza que aparece, em todo caso, no fim desse debate é que uma memória não poderia ser concebida como uma esfera plena, cujas bordas seriam transcendentais históricos e cujo conteúdo seria um sentido homogêneo, acumulando ao modo de um reservatório: é necessariamente um espaço móvel de divisões, de disjunções, de deslocamentos e de retomadas, de conflitos de regularização... Um espaço de desdobramentos, réplicas, polêmicas e contra-discursos.

(PÊCHEUX, 1999, p. 56).

O trabalho com a linguagem assim se tece nesse encontro de redes de dizeres e de efeitos em redes. Assim também nos parece ser pertinente a tessitura do fazer filosófico e da teoria do rizoma, articulações dentre e dentro de redes que se montam e desmontam. Por fim, o trabalho com a informação também reclama a compreensão e a interpretação de documentos e dados que sozinhos pouco dizem, mas que precisam ser pensados dentro de um campo maior de articulações. Quiçá os sujeitos o façam dessa maneira. 


\section{Referências}

BROUGHTON, V. B. Vickery and the Classification Research Group: the legacy of faceted classification. In: NATIONAL ISKO UK CONFERENCE, 2, 2012, Londres. Proceedings..., Londres: ISKO, 2012. p. 315-326. Disponível em: < http://www.iskouk.org/conf2011/papers/ broughton.pdf>. Acesso em: 21 jun. 2014.

BUSH, Vannevar. As We May Think. The Atlantic Monthly, 1945. Disponível em <http://web.mit.edu/STS.035/www/PDFs/think.pdf >. Acesso em: 25 jun. 2014.

DELEUZE, G. Abecedário de Gilles Deleuze - P de professor (parte 3). Disponível em: $<$ https://www.youtube.com/watch ?v=hQ6f0KClnc8>. Acesso em: 05 jun. 2014.

DELEUZE, G.; GUATTARI, F. O que é Filosofia? 3. ed. Rio de Janeiro: Editora 34, 2010. $271 \mathrm{p}$. v.1. $127 \mathrm{p}$.

Mil platôs: capitalismo e esquizofrenia 2. 2. ed. Rio de Janeiro: Editora 34, 2011.

DIAS, F. S.; NASSIF, M. E. Migração conceitual e patologia metodológica: análise da incorporação do conceito rizoma aos estudos da informação. Perspectivas em Ciência da Informação, Belo Horizonte, v. 16, n. 2, p. 147-166, abr./jun. 2013.

KOBASHI, N. Y.; SANTOS, R. N. M. Institucionalização da pesquisa científica no Brasil: cartografia temática e de redes sociais por meio de técnicas bibliométricas.

Transinformação, Campinas, v. 18, n. 1, p. 27-36, 2006.

MAINGUENEAU, D. Gênese dos Discursos. Curitiba: Criar, 2005. 189 p.

MATTELART, A. História da sociedade da informação. São Paulo: Edições Loyola, 2002. $197 \mathrm{p}$.

MONTEIRO, S. D. A organização virtual do conhecimento no ciberespaço.

DataGramaZero, Rio de Janeiro, v. 4, n. 6, p. 1-28, dez. 2003.

MOSTAFA, S. Filosofia da diferença e a ciência da informação. Rio de Janeiro: E-papers, 2013. 125p.

Epistemologia ou filosofia da ciência da informação? Informação \& Sociedade, João Pessoa, v.20, n.3, p. 65-73, set./dez. 2010.

NOVA CRUZ, D. V. Para entender a filosofia de Gilles Deleuze \& Félix

Guattari. Campinas, Alínea, 2009. 122 p.

Patchwork como princípio de produção e organização do conhecimento.

DataGramaZero, Rio de Janeiro, v.12, n.1, fev. 2011.

Informação-afeto: real sem ser atual, ideal sem ser abstrata. 2014. No prelo. 
OLSON, H. A. A potência do não percebido: Hegel, Dewey e seu lugar na corrente principal do pensamento classificatório. InCID: Revista de Ciência da Informação e Documentação, Ribeirão Preto, v. 2, n. 1, p. 3-15, 2011.

PÊCHEUX, M. Semântica e Discurso. Campinas: Unicamp, 1997.

O papel da memória. In: ACHARD, Pierre et al (Orgs.) O papel da Memória 1. Campinas: Unicamp, 1999.

Discurso: estrutura ou acontecimento. Campinas: Pontes, 1990.

PIEDADE. M. A. R. Introdução a teoria da classificação. 2. ed. Rio de Janeiro: Interciência, 1983. 221p.

PINHEIRO, L. V.; SILVA, E. L. As redes cognitivas na Ciência da Informação brasileira: um estudo nos artigos científicos publicados nos periódicos da área. Ciência da Informação, Brasília, v. 37, n. 3, p. 38-50, set./dez. 2008.

ROMÃO, L. M. S.; MOSTAFA, S. P. Acontecimento em Michel Pêcheux e Gilles Deleuze: contribuições ao campo da informação. In: MOSTAFA, S. P. Filosofia da diferença e a ciência da informação. Rio de Janeiro: E-papers, 2013. p. 95-108. 